\title{
POSGUERRA E IMPLICACIÓN DE LOS RESIDENTES EN IBIZA
}

\author{
José Ramón Cardona \\ Doctor en Economía de la Empresa. Universitat de les Illes Balears (Espa- \\ ña). E-mail: jramon.cardona@terra.com
}

\section{Antoni Serra Cantallops}

Profesor Titular de Comercialización e Investigación de Mercados. Universitat de les Illes Balears (España).E-mail: antoni.serra@uib.es

\section{Resumen}

Ibiza es una isla del Mediterráneo con una enorme dependencia económica del turismo. Se trata de un destino turístico conocido por su oferta de sol y playa, complementada con una oferta de ocio nocturno de fama mundial. Aunque el sector turístico apareció en la isla en el primer tercio del siglo XX, la Guerra Civil Española, la Segunda Guerra Mundial y el bloqueo internacional al régimen franquista borraron el turismo de la isla durante una década. Pero los sufrimientos y miserias económicas que causaron hicieron renacer el turismo con mayor fuerza al producirse una creciente implicación de los residentes en el nuevo sector. Esta implicación junto con la tolerancia hacia las costumbres de los turistas lanzaron a la isla hacia un Boom turístico con impacto mediático internacional. En este trabajo se pretende mostrar que Ibiza sirve de ejemplo de la importancia de estos dos elementos (implicación y tolerancia) para el desarrollo turístico de una región.

Palabras clave: Ciclo de Vida del Destino Turístico, Ibiza, actitudes de los residentes, implicación de los residentes, tolerancia de los residentes. 


\title{
POST-WAR AND INVOLVEMENT OF RESIDENTS IN IBIZA
}

\author{
José Ramón Cardona \\ Doctor en Economía de la Empresa. Universitat de les Illes Balears (Espa- \\ ña).E-mail: jramon.cardona@terra.com
}

\section{Antoni Serra Cantallops}

Profesor Titular de Comercialización e Investigación de Mercados. Universitat de les Illes Balears (España).E-mail: antoni.serra@uib.es

\begin{abstract}
Ibiza is a Mediterranean island with a very strong economic dependence on tourism. Ibiza is a tourist destination known for its sun and beach offer, complemented by a range of world-famous nightlife. Although the tourism industry on the island appeared in the first third of the twentieth century, the Spanish Civil War, the Second World War and the international blockade to the Franco's regime wiped out tourism in the island for a decade. But the sufferings and economic miseries derived from these political facts boosted tourism revival more strongly on the island due to increased involvement of residents in the new industry. Residents' involvement coupled with a spirit of tolerance to the habits of visitors fostered the island towards a 'tourism boom' that received international media coverage. This paper aims to show that Ibiza is a good example of the importance of these two elements (involvement and tolerance) for tourism development in a region.
\end{abstract}

Keywords: Tourism Destination Life Cycle, Ibiza, residents' attitudes, residents' involvement, residents' tolerance. 


\section{INTRODUCCIÓN}

Las actitudes de los residentes pueden verse influenciadas por la fase del ciclo de vida en que se encuentre el destino turístico (Johnson et al, 1994; Williams y Lawson, 2001). No es lo mismo una región en sus inicios turísticos que un destino consolidado y masificado. El grado de desarrollo turístico es un elemento con gran influencia en las percepciones y actitudes de los residentes (Mason y Cheyne, 2000; Murphy, 1985; Pizam, 1978) y, por tanto, es lógico que las actitudes cambien con el paso del tiempo.

En esencia, para entender las actitudes de los residentes en un destino turístico consolidado antes hay que analizar la evolución turística de la región. Es importante conocer la evolución cuantitativa y la tipología turística en las diversas etapas, ya que esto determina la evolución de las actitudes de los residentes (Allen et al, 1988; Jurowski, 1994; Mason y Cheyne, 2000; Martin y Uysal, 1990; Murphy, 1983; Murphy, 1985; Pizam, 1978; Ritchie, 1988; Williams y Lawson, 2001), y también se deben averiguar las actitudes de los residentes en las diversas épocas de desarrollo turístico, ya que influyen en el tipo de turismo y en las actitudes futuras por vía directa, interacción entre residentes, e indirecta, a través de los turistas (Murphy, 1985).

Ibiza es una isla del Mediterráneo Occidental que se caracteriza por una enorme dependencia económica del turismo. En la actualidad más de 130.000 personas (134.460 a 1 de enero de 2011) residen en los 572,56 km2 de superficie de la isla, según datos del INE, y conviven con cerca de dos millones anuales de turistas, cuya presencia se concentra principalmente en los meses de junio a septiembre. El desarrollo turístico ha causado cambios drásticos en la isla y su sociedad, habiendo un antes y un después del turismo. De las diversas fases del ciclo de vida por las que ha pasado el desarrollo turístico de Ibiza, las iniciales resultan claves para entender por qué y cómo se inició el turismo en esta isla.

El primer tercio del siglo XX representa la implantación del turismo como sector económico, aunque con un peso marginal en la economía local y sin implicación por parte de la inmensa mayoría de la población. Tras la debacle que representa la Guerra Civil Española, seguida por la Segunda Guerra Mundial y los años de embargo internacional, el turismo consigue resurgir. Son catorce años los necesarios para recuperar los niveles anteriores a la Guerra Civil, pero la experiencia vivida hace que el nivel de implicación de la población sea mucho mayor que antes y el desarrollo muy acelerado. Este periodo coincide con la fase de implicación del ciclo de vida descrito por Butler (1980) y en Ibiza puede considerarse que llega hasta la abertura del aeropuerto de Ibiza en 1958. 
Según datos del INE referentes a los censos de la época, la población de derecho era de 35.441 habitantes en 1940 y de 34.339 habitantes en 1960, dando como resultado una pérdida de población del 3,11\% vía emigración. Los municipios con datos menos negativos son los dos con incipiente turismo, Ibiza ciudad y Sant Antoni. Probablemente

nos encontramos ante la época más dura de todo el siglo XX. Esta es la última etapa de la historia de la isla en que el sector primario tiene un peso predominante aún, a pesar de que mucha población, especialmente jóvenes, se empieza a volcar en el nuevo sector. Nuestro objetivo es describir la evolución del turismo y que actitudes mostraban los residentes en la fase de implicación que vivió Ibiza en los años cuarenta y cincuenta. A partir de los años cincuenta las fuentes documentales aumentan significativamente por dos motivos: la cercanía temporal facilita que las personas que vivieron esa época sigan vivas, y existe un aumento de las personas conscientes de la trascendencia de documentar ese momento y la sociedad local. Este hecho permite disponer de mayor información para conocer la sociedad que en épocas anteriores, aunque siempre con las limitaciones que conllevan las fuentes secundarias.

\section{FASE DE IMPLICACIÓN}

En esta fase se produce la recuperación de los avances realizados en los años treinta y perdidos con la Guerra Civil, la Segunda Guerra Mundial y la posguerra, y se crea un potente sector turístico que a finales de los años cincuenta ya no sólo es importante para la economía local sino que se está convirtiendo en el principal (Cirer, 2004: 239). En un estudio publicado en Diario de Ibiza en el año 1956, y referente a 1955, se cuantificaban unos ingresos netos por turismo de más de 41 millones de pesetas, mientras que los ingresos por exportaciones sobrepasaban ligeramente los 37 millones de pesetas (Ramón, 2001: 83-84). La Fase de Implicación se puede subdividir según la tendencia del crecimiento del sector en dos partes: antes de 1950 y después de 1950.

De 1936 a 1950 se produjo un paréntesis provocado por la Guerra Civil Española, la Segunda Guerra Mundial y los primeros, y más duros, años de posguerra, bloqueo internacional y política autárquica. A su vez se pueden diferenciar dos partes dentro de este periodo: de 1936 a 1946 los avances del periodo 1931-1936 se hunden, y sólo queda alguna pensión abierta y la presencia esporádica de algún extranjero. A partir de 1946 se inician los intentos por recuperar lo que se ha perdido a causa de las guerras, a pesar de los fuertes problemas económicos y legales que padece el sector. El esfuerzo de los empresarios locales y la relajación de diversas normas permitieron que en 1950 se recuperara la situación de 1935. 
A partir de 1950 el sector turístico recupera y continúa por la senda que había iniciado antes de la Guerra Civil: aumenta la oferta de plazas, regresan los artistas e intelectuales que abandonaron la isla en 1936 y aparecen los beatniks. Esta década se caracteriza por el liderazgo del sector y cosmopolitismo de la Bahía de Sant Antoni, y por el predominio de los turistas franceses. A partir de 1955 aumenta el crecimiento en la llegada de turistas a causa del establecimiento de líneas directas con la península durante el verano. En 1958, con la apertura del aeropuerto se produce un nuevo aumento en la velocidad de crecimiento del sector y un cambio en el tipo de turismo que llega a la isla, empezando el turismo de masas (Cirer, 2004: 239).

La agricultura se recuperará en esta fase, llegando a los niveles de antes de la guerra en 1950 (Cirer, 2004: 238), viviendo una buena década en los cincuenta pero a finales de esa década se produce su caída definitiva y en los años sesenta, con la patata inglesa, tiene su último momento de prosperidad antes de convertirse definitivamente en un sector residual, dejando al turismo como único motor de la economía (Cirer, 2002).

En cuanto a las actitudes de los residentes, en esta fase hay un cambio importante respecto a las décadas anteriores y es que la mayor parte de la población toma conciencia de las ventajas del turismo y empieza a implicarse en el sector gracias al acicate que representó para la población local las miserias de la posguerra.

\section{La Posguerra}

La Guerra Civil Española, la II Guerra Mundial y el posterior bloqueo al que la comunidad internacional sometió a España en protesta por la dictadura de Franco (Cirer, 2004: 172; Ramón, 2001: 67-68) causaron la desaparición del turismo. Años de trabajo para levantar el sector se habían perdido y era preciso volver a empezar. La posguerra y el periodo de autarquía significaron un intento por recuperar lo perdido y en 1950 se consiguen superar las cifras de antes de la guerra (Ramón, 2001: 9). Hans Hinterreiter residió en Ibiza de noviembre de 1934 a julio de 1936. En 1939 regresó a Ibiza: "En Ibiza todo estaba mucho más triste. [...] Todos los extranjeros estaban ausentes durante estos primeros años. Sólo recuerdo dos alemanes y yo [...]. Más adelante, en la década de los cincuenta, llegaron algunos de los alemanes que habían salido" (Planells, 1986: 120). A la década de los cuarenta podríamos denominarla "la década perdida", pues entre la Segunda Guerra Mundial, el posterior boicot a España y la situación económica europea, el panorama resultante era de parálisis turística casi total. De esta época sólo hay algunos datos anecdóticos, de poca trascendencia más allá de reflejar la situación social existente y, sobre todo, el talante de las nuevas autoridades en materia turística, que era más bien de recelo hacia la llegada de veraneantes. El régimen franquista, en su primera etapa, se caracterizó por una actitud totalmente cerrada a la afluencia de visitantes procedentes del exterior (Ramón, 2001: 68-69). Muestra del nuevo talante es el bando de la Delegación 
Gubernativa, de 4 de julio de 1941, sobre los baños de mar que recordaba la obligación que tenían los ciudadanos de acudir a la playa separados, en función de los sexos. Y se advertía: "Se dispondrá la debida vigilancia para el cumplimiento de la distribución acordada y se castigarán las infracciones" (Ramón, 2001: 69).

En agosto de 1945 aparecía en el Diario de Ibiza una gacetilla que, haciendo una introducción favorable sobre el turismo termina advirtiendo sobre sus efectos sobre la moral y las costumbres locales:

"Ni andamos tan alicaídos que pudiera extasiarnos ver convertido en casa de... huéspedes sin decoro nuestro solar honrado. Lo cual no es mera fantasía escrupulosa. No cabiendo olvidar, con nuestra dignidad, que todo lo extravagante y dislocado tiene pegadizas influencias, y viniendo de fuera, con afeites de moda y de presunto señorío, más. [...] ¿Quieren sugerir estas líneas una postura de hostilidad frente al turismo? No. De simple vigilancia. Sobre lo advenedizo en quienes corresponda, y de propia conducta, previniendo inadecuadas complacencias y simiescas imitaciones, en el estado llano" (Diario de Ibiza, 12 de agosto de 1945).

Este texto representa de forma bastante adecuada la opinión hostil que una parte importante de los poderes locales de la posguerra tenía acerca del turismo (Ramón, 2001: 70).

La situación hotelera en la isla era caótica. Desde 1936 y hasta el final de la Segunda Guerra Mundial los hoteles de la ciudad estuvieron ocupados militarmente; los de Santa Eulària cerrados, y sólo los de Sant Antoni permanecieron abiertos. Los únicos hospedajes que funcionaban en la ciudad eran Fonda la Marina y Fonda del Comercio, establecimientos de pequeñísima capacidad y larga tradición como hospedería. Las autoridades y demás personas que visitaban la isla tenían que pernoctar en Sant Antoni por carecer de alojamientos de calidad en Ibiza capital (Cirer, 2004: 172, 183-184; Planells, 1984: 266; Ramón, 2001: 70).

En junio de 1946, se reinauguró el antiguo Gran Hotel con el nombre de Hotel Ibiza. Sus nuevos responsables lograron que la ciudad contase con un hotel de calidad, pero económicamente fue un desastre. Por aquel entonces todos los productos básicos estaban racionados, pero los hoteles, al no disponer de cupo alguno, debían abastecerse en el mercado del estraperlo, con precios muy elevados. Además había problemas con el agua corriente, la corriente eléctrica, etc. unido a unos precios bajísimos de los alojamientos, incluso para aquella época. Debe tenerse en cuenta que las tarifas estaban reglamentadas y constantemente inspeccionadas (Cirer, 2004: 183-185; Ramón, 2001: 71-73). El 1 de junio de 1950, se hizo cargo de la explotación Antoni Planells Ferrer que intentó capear 
los problemas hasta que ocho años más tarde tuvo que dejar la gestión por razones de salud. El propio Planells cuenta que:

"A más clientela surgieron más dificultades. A la mayoría de las que tenían mis antecesores se sumaron un mercado completamente desabastecido que me obligo a traer ensaladas y otros productos de Barcelona, y ternera de Mallorca; falta de personal profesional; al no haber pan por estar racionado, tener que comprar bollos de pastelería; la competencia desleal, de casas particulares y establecimientos no legalizados, que alquilaban habitaciones a cinco pesetas, etc. Por si esto fuera poco, el Excmo. Ayuntamiento colocó un guardia municipal, al que ayudaban gratuitamente algunos 'puritanos' frente al Hotel Ibiza, en la confluencia de la avenida Bartolomé Ramón con el paseo de Vara de Rey. La finalidad de esta vigilancia era mantener 'la moral' de algunos ciudadanos que no veían en el turismo su salvación" (Planells, 1984: 276).

La competencia ejercida por casas particulares no era desdeñable y se calcula que hasta un $50 \%$ de los veraneantes optaban por alojarse en viviendas. La denuncia que hace Antoni Planells de la competencia desleal muestra que muchos ibicencos vieron en los turistas y visitantes de la época una fuente de riqueza que les ayudara a combatir las miserias que aun se arrastraban en la isla. Las carestías provocadas por la posguerra y el boicot, junto con la moral franquista y las medidas de mantenimiento de esta moral, causaron que hasta muy entrados los años cincuenta apenas se produjera un crecimiento perceptible de la industria turística (Cirer, 2004: 186; Ramón, 2001: 71-73). Además, la situación era diferente en la capital y en Sant Antoni. Antonio Planells lo cuenta así:

"El baile de sociedad y los clubes nocturnos estaban prohibidos en la isla de Ibiza, en cambio en San Antonio se bailaba todas las noches en la terraza de un café, cercano al ayuntamiento de dicha villa. Tampoco a las señoras se les molestaba por su modo de vestir, y no pasaba nada. O mejor dicho, si pasaba con muchos clientes de nuestro Hotel [Ibiza] que habían ido de excursión a San Antonio, algunos pedían la cuenta y se marchaban a dicha villa porque allí había 'playa'" (Planells, 1984: 276-279). 


\section{Cuadro $N^{0} 1$ : Oferta de alojamiento en la isla de Ibiza en 1950.}

\begin{tabular}{|lcc|}
\hline Municipio & Habitaciones & Plazas \\
\hline Ibiza (Capital) & $\mathbf{1 1 0}$ & $\mathbf{1 8 4}$ \\
\hline Hotel Ibiza (Gran Hotel) & 72 & 126 \\
Pensión España & 18 & 26 \\
Pensión La Marina & 7 & 12 \\
Pensión El Comercio & 8 & 13 \\
Pensión Avenida & 5 & 7 \\
\hline Sant Antoni & $\mathbf{1 1 4}$ & $\mathbf{2 0 6}$ \\
\hline Hotel Ses Sevines & 15 & 27 \\
Hotel Portmany & 18 & 33 \\
Hotel San Antonio & 20 & 37 \\
Pensión Esmeralda & 14 & 27 \\
Pensión Miramar & 11 & 19 \\
Pensión Maricel & 19 & 33 \\
Pensión Playa & 17 & 30 \\
\hline Santa Eulària & $\mathbf{4 9}$ & $\mathbf{9 1}$ \\
\hline Hotel Cosmi & 10 & 20 \\
Pensión Royalty & 4 & 8 \\
Pensión Buenavista & 14 & 22 \\
Pensión Sa Rota & 12 & 23 \\
Pensión Central & 9 & 18 \\
\hline Total & $\mathbf{2 7 3}$ & 481 \\
\hline
\end{tabular}

Fuente: Ramón (2001).

El hecho de que los carabineros y el Ayuntamiento de Sant Antoni hicieran todo lo posible para que la guerra tuviera el mínimo impacto en el pueblo, permitió que sus establecimientos permanecieran abiertos y las normas referentes a la moral pública se relajaran enormemente. Esta diferencia hizo que el liderazgo que había tenido la capital en los años treinta se perdiera en favor de Sant Antoni. El liderazgo de Sant Antoni se mantuvo con mucha claridad hasta los años del boom turístico, destacando dentro de este periodo los años cincuenta.

El 21 de septiembre de 1947 se produjo el restablecimiento de la línea Ibiza-Barcelona inaugurada en 1909 e interrumpida en 1936 por la Guerra Civil. Este servicio era importantísimo no sólo para los residentes sino también para incrementar una incipiente corriente de veraneantes hacia Ibiza. Pero las comunicaciones seguían siendo escasas y los problemas de suministros e infraestructuras limitaban el futuro del turismo (Cirer, 2004: 211; Ramón, 2001: 74; Torres, 1961). A partir de 1949 aparecieron algunas normas que facilitaron la actividad turística. Muchas veces los cambios no se reflejaban en un reglamento publicado en el BOE sino en instrucciones a los gobernadores civiles para que apliquen la normativa existente con poco rigor o simplemente que la ignoren (Cirer, 2004: 189).

En 1950 las camas ofertadas eran 481 (Cuadro 1), mientras que en 1935 eran 473 (Ramón, 2001). Habían reabierto algunos establecimientos, otros no volvieron a abrir y se abrieron algunas pensiones nuevas, el resultado es que se estaba en 1950 en el punto en que se 
había quedado el desarrollo turístico antes de la Guerra Civil (Cirer, 2004: 216).

\section{Cuadro $\mathrm{N}^{0}$ 2: Viajeros alojados en los establecimientos de la isla de Ibiza en 1950.}

\begin{tabular}{|lccc|}
\hline \multicolumn{1}{|c}{ Municipio } & Viajeros & Estancias & $\begin{array}{c}\text { Estancia } \\
\text { media }\end{array}$ \\
\hline Ibiza (Capital) & 1.503 & 6.468 & 4,30 \\
Sant Antoni & 1.326 & 14.876 & 11,22 \\
Santa Eulària & 351 & 7.314 & 20,84 \\
\hline Total & $\mathbf{3 . 1 8 0}$ & $\mathbf{2 8 . 6 5 8}$ & $\mathbf{9 , 0 1}$ \\
\hline
\end{tabular}

Fuente: Ramón (2001).

En 1950, la estancia media en la capital era de 4,3 días, lo que nos indica que la mayoría de los clientes eran comerciantes o representantes desplazados a la isla por razones de negocios. En Sant Antoni la media se sitúa en 11,2 días, la normal en un destino puramente turístico. En Santa Eulària, la cifra es de 20,8 días (Cuadro 2), forzosamente alterada por muchos artistas y escritores que utilizaban los hoteles o pensiones como residencia de sus largas estancias en la isla (Ramón, 2001).

La década de los cincuenta: empieza el despegue del sector.

El levantamiento del embargo de la ONU a España, en 1950, propició un aumento en el número de viajeros llegados a la isla y a finales de los años cincuenta el turismo es el sector con mayor peso en las exportaciones de la isla (Ramón 2001: 83-84). En el periodo 1958-1964, se producirá la transición definitiva de una economía en la que conviven las exportaciones de productos del campo con el turismo a una economía basada, de forma aplastante, en el turismo (Cirer, 2004: 217).

Entre 1950 y 1955 se produjo un significativo aumento de las plazas ofertadas, doblándose la oferta de alojamiento (1.014 camas). Además los nuevos establecimientos eran de un tamaño mucho mayor y de una categoría superior a la planta hotelera anterior. Entre 1955 y 1960 la oferta de plazas turísticas se triplicó, llegando a las 1.836 habitaciones y 3.357 camas (Cirer, 2004: 216-218; Ramón, 2001: 80). Si tenemos en cuenta el número de turistas llegados en 1960 (24.402) y que en ese año el número de estancias registrado fue de 269.178, obtendríamos un número de estancias por turista de 11,03 días y una ocupación media de cama/año de 83,31 días, que para las camas totalmente turísticas llegaría a significar ocupaciones medias por temporada de más del 85\% (Ramón, 2001: 90). Planells lo comenta: "Es a partir de 1955 cuando Eivissa [Ibiza capital], Sant Antoni, Santa Eulària, se abren a una incipiente actividad. Construcciones de chalets y locales, sin pausa, sin apenas capital, van moteando las bahías. Muchas de las casas, algunas 
de dos alturas en Figueretes y Es Viver, que cobijarían a tantos beatniks y artistas se construyen en estos momentos" (Planells, 2002: 14).

Los primeros datos fidedignos de las entradas de turistas son del año 1954. De los años anteriores no hay más que algún testimonio aislado y datos muy indirectos (Cirer, 2004: 209). Por ejemplo, José Zornoza (1964) mencionaba el año 1947 como el primero en que reaparece algún turista en Ibiza después de la guerra. Cirer (2004: 209) y Planells (1984) estimaban que entre 1950 y 1953, nunca llegaron a Ibiza más de 5.000 turistas por año. A partir de 1955, con el establecimiento de las líneas marítimas de verano, y de 1958, con la apertura del aeropuerto, se produce una aceleración en el crecimiento del número de llegadas. Zornoza (1964), utilizando datos de pasajeros llegados a Ibiza, realiza las estimaciones del total de turistas para algunos años: 10.572 turistas en 1954, 18.663 turistas en 1957 y 31.722 turistas en 1960.

Entre los turistas extranjeros, la nacionalidad dominante en un primer momento era la francesa. Hasta 1957 los franceses eran más del 25\% del total de turistas, pero después fueron perdiendo presencia a favor de, sobre todo, los ingleses (Cirer, 2004: 210). El hotelero Vicent Juan Guasch rememora los orígenes del turismo francés:

"A finales de los años cuarenta y con motivo de un acontecimiento religioso de carácter internacional que tuvo lugar en Barcelona, Voyages Fram de Toulouse llevó a miles de franceses a Cataluña [...]. A esas personas se les dio a conocer el Mediterráneo español. En los comienzos de aquel programa, Ibiza representó un corto periodo, un intermedio. Los clientes viajaban en tren desde París y sus alrededores hasta Toulouse, a veces hasta Perpiñán, y después continuaban en autocar hacia Barcelona para seguir hasta Ibiza en barco. En esa época, la frecuencia de viajes en barco desde Barcelona a la isla era de uno semanal. Los franceses se sintieron atraídos por el encanto y el embrujo de Ibiza. [En Ibiza] había unas auténticas ganas de intercambio de culturas, costumbres, idiomas. En esa época, Ibiza ofrecía un tipismo, una tranquilidad, una hospitalidad. En resumen, la isla constituía un lugar irresistible, con sus gentes abiertas, tolerantes, y con un verdadero deseo incontenible de empezar la apertura. Al mismo tiempo, los ibicencos querían comunicarse con el mundo exterior y, como sus principales visitantes eran los franceses, la Alianza Francesa obtuvo un enorme éxito" (Ramón, 2001: 80-81).

Pero no todos eran franceses. El mercado alemán comenzó a emerger también en la década de los cincuenta, concretamente a partir de 1956. La prodigiosa recuperación económica que, sólo diez años después de terminada la II Guerra Mundial, comenzaba a experimentar Alemania hizo que fuera aumentando la cantidad de alemanes que salían de nuevo a pasar sus vacaciones fuera del país. Los turistas alemanes venían en grupos que primero volaban hasta Palma y después llegaban a Ibiza en barco. La ventaja que 
ya entonces ofrecían los alemanes era su elevado poder adquisitivo (Ramón, 2001: 82).

Si en los años cincuenta los turistas predominantes son los franceses, seguidos de los españoles, la zona turística por excelencia en Ibiza es Sant Antoni. Hasta 1960 la bahía de Sant Antoni de Portmany concentraba entre la mitad y dos tercios de las plazas de la isla (Cirer, 2001; Cirer, 2004: 216-218) y casi monopolizaba el crecimiento en plazas y en turistas (Buades, 2004: 172). Esta fue la primera zona en desarrollarse turísticamente, y ya tenía una importante presencia de turistas a finales de los años cincuenta, pero en las décadas posteriores su crecimiento ha sido más moderado que el de otras zonas como Sant Josep o Santa Eulària. El periodista Fernando-Guillermo de Castro comenta como era la bahía de Sant Antoni a finales de los cincuenta: "En Sant Antoni se puede decir que se conocía y se trataba todo el mundo. Los lugareños alternaban con los residentes extranjeros, que eran pocos, y con los veraneantes peninsulares habituales; incluso con algunos turistas con los que se mezclaban en bares y salas de fiestas. San Antonio era la capital turística de la isla, sin menoscabo de la ciudad y de Santa Eulària" (de Castro, 2003: 33).

Antonio Hormigo, ibicenco que vivió y trabajó en el Sant Antoni de los años cincuenta, recuerda que los primeros turistas que llegaron a Sant Antoni después de la guerra eran "los franceses del Club de los Argonautas, y que estaban en Can Tarba" (Planells, 1980: 185), además comenta que "muy pronto llegó el progreso y a nosotros nos encantaba que se construyeran muchos hoteles, porque Sant Antoni crecía" (Planells, 1980: 187). Antonio Hormigo puede considerarse un ejemplo de una de las primeras generaciones de ibicencos que adoptaron una forma de vida a imitación de los extranjeros que residían o visitaban la isla. Estos ibicencos se caracterizaban por tener un nivel de estudios que se reducía a la enseñanza obligatoria y lo que habían leído por su cuenta, hablaban a un nivel turístico diversos idiomas (inglés, francés, alemán, italiano, etc.), trabajaban en actividades vinculadas al creciente sector turístico y, por la noche, frecuentaban con asiduidad los establecimientos con predominio de los turistas y los residentes extranjeros. Pero no todo eran voces entusiastas, los extranjeros que llegaron a la isla buscando un lugar de residencia tranquilo y económico empezaban a preocuparse por los cambios que sufría la Bahía. Hans Hinterreiter comenta que "en 1953 yo estaba asustado por la inflación. Sant Antoni estaba inaugurando ya la época del turismo. Vi que se construían los primeros hoteles en la bahía y yo necesitaba otro rincón" (Planells, 1986: 121).

En 1955 se establecieron servicios extraordinarios de trasporte marítimo con el exterior en los meses de julio, agosto y septiembre. Este hecho permitió aumentar de forma significativa las llegadas de turistas pero tuvieron una consecuencia inesperada, incrementaron la estacionalidad del turismo. De los 24.402 turistas que se alojaron en establecimientos hoteleros en 1960, el 65\% lo hizo en los meses de julio, agosto y 
septiembre, aquellos en los que había disponibilidad de billetes. Este incremento de la estacionalidad hizo que los hoteleros ibicencos optaran por cerrar los establecimientos en invierno y abrir sólo durante los meses de verano (Cirer, 2004: 211-212). Aunque a partir de 1955 se aumentó la frecuencia de los buques que unían Ibiza con la península, la calidad del servicio ofrecido con estos barcos era claramente mejorable: "A esta isla de finales de los cincuenta se llega con barcos lentos" (Lee, 1975).

El aeropuerto se había convertido en los años cincuenta en un objetivo común de todos los ibicencos, ya que era visto como una mejora imprescindible. Esta instalación fue posible por los fondos procedentes de la Administración Central, pero también por las aportaciones particulares que muchas personas y empresas realizaron de forma totalmente desinteresada. En realidad, en aquella época la Administración difícilmente realizaba una obra pública de estas características si la población del lugar no colaboraba, y se colaboró enormemente (Ramón, 2001: 76-77).

El aeropuerto de Es Codolar fue construido en 1936, debido a la Guerra Civil, como aeródromo militar de emergencia pero permaneció como aeródromo principalmente militar hasta el 1 de junio de 1958, cuando se abrió al tráfico comercial (Soriano, 1996). La jornada del 1 de junio de 1958 revistió carácter de día histórico y la inauguración oficial (llegada del primer avión de pasajeros) se desarrolló en medio de un ambiente de gran expectación (Cirer, 2004: 213; Ramón, 2001: 78-79). Posteriormente se realizaron muchas mejoras en el aeródromo con el objetivo de convertirlo en un aeropuerto totalmente operativo. A partir de 1964 el aeropuerto de Ibiza pudo empezar a operar con normalidad, aunque los vuelos internacionales no pudieron aterrizar en el aeropuerto hasta que se habilitó la aduana en 1966 y el aeropuerto adquirió la categoría de internacional (Cirer, 2004: 213). Con la apertura del aeropuerto al tráfico internacional, el turismo de masas contratado por turoperadores comienza a llegar a la isla.

A partir de 1958 la situación general mejoró. Los años anteriores a 1958 llegaban entre 13.000 y 14.000 personas, en 1958 se produjeron casi 19.000 llegadas (Ramón, 2001: 80). Antoni Planells comenta:

"A mediados de 1958 cambia radicalmente la situación, hubo un importante incremento de las comunicaciones marítimas, se inauguró el aeropuerto, se incrementaron los precios de los alojamientos, desapareció el control de divisas y se simplificaron los trámites en las aduanas. GESA instaló una potente central eléctrica [...] aumentó la demanda de alojamientos y las agencias comenzaron a anticipar dinero, a descontar un tanto por ciento de las facturas, se conceden créditos oficiales a bajo interés, se establecen los precios a primeros de año, etc. En estas condiciones, preparado como estaba el terreno, la afluencia turística aumenta de año en año" (Planells, 1984). 


\section{Cuadro $N^{0}$ 3: Evolución de los turistas llegados a Ibiza en la segunda mitad de los} cincuenta.

\begin{tabular}{|l|rc|rc|r|}
\hline \multirow{2}{*}{ País de Origen } & \multicolumn{2}{|c|}{$\mathbf{1 9 5 5}$} & \multicolumn{2}{|c|}{$\mathbf{1 9 6 0}$} & \multicolumn{1}{c|}{ Var. } \\
& Turistas & \multicolumn{1}{c|}{$\%$} & Turistas & \multicolumn{1}{c}{$\%$} & $\mathbf{1 9 5 5 / 1 9 6 0}$ \\
\hline Reino Unido & 2.633 & $18,70 \%$ & 7.092 & $29,06 \%$ & $169,35 \%$ \\
España & 3.348 & $23,77 \%$ & 5.878 & $24,09 \%$ & $75,57 \%$ \\
Francia & 3.969 & $28,18 \%$ & 4.918 & $20,15 \%$ & $23,91 \%$ \\
Alemania & 2.139 & $15,19 \%$ & 3.175 & $13,01 \%$ & $48,43 \%$ \\
Suiza & 471 & $3,34 \%$ & 559 & $2,29 \%$ & $18,68 \%$ \\
Estados Unidos & 268 & $1,90 \%$ & 445 & $1,82 \%$ & $66,04 \%$ \\
Bélgica & 374 & $2,66 \%$ & 371 & $1,52 \%$ & $-0,80 \%$ \\
Suecia & 257 & $1,82 \%$ & 492 & $2,02 \%$ & $91,44 \%$ \\
Otros & 624 & $4,43 \%$ & 1.472 & $6,03 \%$ & $135,90 \%$ \\
\hline Total & $\mathbf{1 4 . 0 8 3}$ & & $\mathbf{2 4 . 4 0 2}$ & $\mathbf{7 3 , 2 7 \%}$ \\
\hline
\end{tabular}

Fuente: Zornoza (1964) y elaboración propia.

Otro cambio importante que sucedió en 1958 fue que el turismo predominante en la isla pasó de ser el francés a ser el inglés (Cuadro 3), el cual se ha mantenido hasta la actualidad. Mientras el volumen de turistas franceses evolucionaba despacio (aumentan un $24 \%$ entre 1955 y 1960), la apertura del aeropuerto de Ibiza facilitó enormemente la llegada de ingleses (aumentan un 170\% entre 1955 y 1960), incrementando su presencia en la isla de forma muy importante (Gráfico 1).

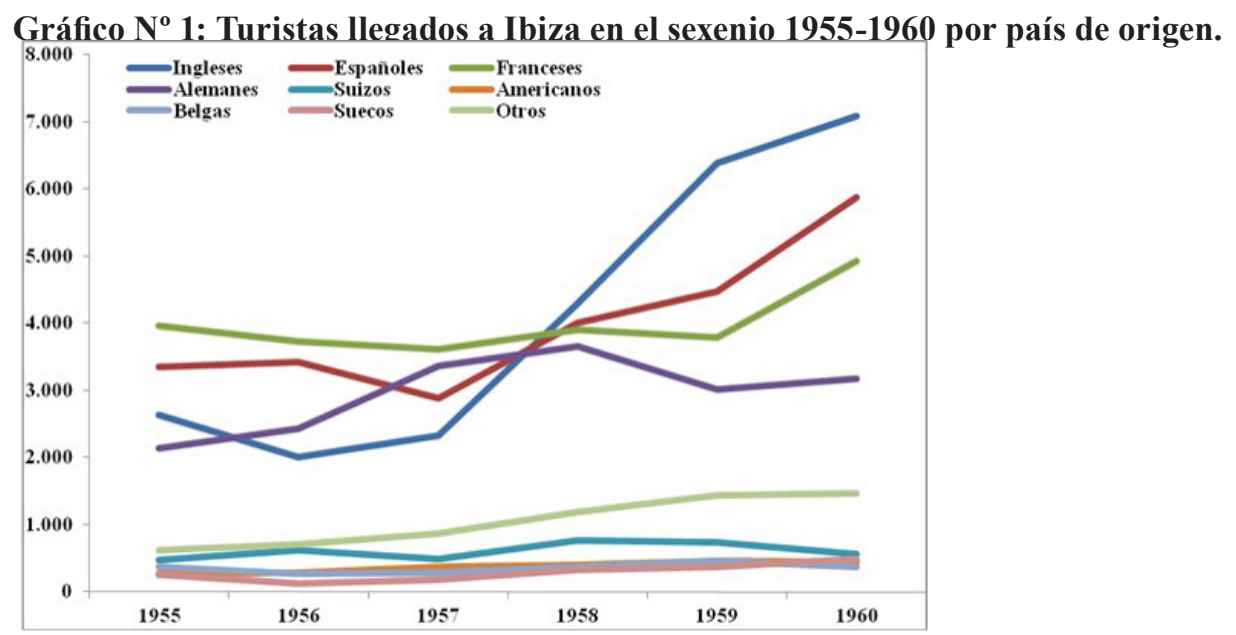

Fuente: Zornoza (1964) y elaboración propia. 
Algunos autores (Cirer, 2004: 210-211) consideran que el cambio en la nacionalidad predominante tiene que ver con el medio de transporte empleado por los turistas. Los franceses venían en barco desde Barcelona, mientras que los ingleses llegaban en avión. Otros autores consideran que el cambio del turismo francés por el inglés a finales de los cincuenta puede considerarse causa de la irrupción masiva de turoperadores británicos, dejando en un puesto testimonial al turismo galo, cuyo país carecía de turoperadores con el empuje necesario (Buades, 2004: 174; Ramón, 2001: 99). Probablemente ambos elementos estén relacionados, ya que los mayoristas suelen usar para sus paquetes turísticos el transporte aéreo y con la apertura del aeropuerto Ibiza era un destino adecuado para los turoperadores. Si a esto sumamos que los franceses y españoles venían mayoritariamente por libre, mientras que los ingleses y alemanes venían mayoritariamente en viajes organizados, se entiende que a partir de 1958 se produjera un importante incremento del número de turistas y un cambio en las nacionalidades predominantes.

\section{Comunidad bohemia y antisistema de los cincuenta.}

En Ibiza, los años cuarenta no significan un lapso especialmente significativo dentro del arte contemporáneo de la isla, como muestra el hecho de que en 1939 regresa Will Faber y Hans Hinterreiter. Los pocos extranjeros que regresan tras la Guerra Civil y la Segunda Guerra Mundial van conformando una nueva forma de vida que ya será descaradamente rupturista a finales de los cincuenta. Artistas, rock, jazz, marihuana, bohemios, existencialistas, generación beat, dejarán paso a una creciente explosión en los años sesenta (Planells, 2002: 9).

En los cincuenta regresa Erwin Broner y llegan nuevos artistas para vivir y trabajar en la isla (Planells, 2002: 37-38): Alan Schmer, André Kuyten, Bert Schierbeeck, Carlos Dudek, Cees Nooteboom, Cliford Irving, Cornelis Bastiaan, David Walsh, Edith Sommer, Elmyr de Hory, Emilio Vedova, Erwin Bechtold, Esteban López, Fernando de Castro, Frank El Punto, Hans Hinterreiter, Hans Laabs, Harry Mulisch, Heinz Trökes, Hugo Claus, Ignacio Aldecoa, Ingeborg, Ivan Spence, Jan Cremer, Jan Gerhard Toonder, Janet Frame, José Fin, Katya Meirowsky, Laurie Lee, Manolo Mompó, Pancho Cossío, Paul Brunswick, Paul Grant, Phil Hoffman, Rafael Azcona, Sioma Baram, Stephen Seley, Tur Costa, Vert Schierbeeck, Vicente Calbet, Waldemar Post, etc. Estos nuevos vecinos empiezan a tomar sitio en las plazas, silla en las mesas donde beben absenta, discuten, pelean, bailan y juegan al ajedrez, dominó o backgammon.

Las bondades de la isla que atrajeron a los extranjeros son enumeradas de forma clara por diversas personas: "El paraíso existía, tenía nombre (Ibiza) y era accesible con una beca de estudiante" (Planells, 2002: 16). Charles Orloff comentaba: "mi llegada a Ibiza 
fue debida a unos amigos que me dijeron que la isla era muy bonita y tremendamente barata, mientras estaba esperando una exposición en Italia. [...] Desde 1951 he estado ya siempre en Ibiza, excepto algunos viajes" (Planells, 1980: 173). Hans Hinterreiter comentaba de su llegada a la isla:

"Estando en Mallorca, un hotelero mallorquín me habló tan mal de Ibiza que no pude resistir la tentación de visitarla. Cuando vi la mole de la ciudad de Ibiza quedé cautivado. Nunca he visto otra más bonita. Estuve solamente catorce días. Pero la belleza de la isla y sus bajísimos precios estaban ya dentro de mi memoria. Ibiza era cuatro veces más barata que Suiza, y yo no tenía dinero" (Planells, 1986: 119).

Los extranjeros que llegaban a la isla buscaban "calor, sol, el mar desinfectante, bebidas frescas y una peseta barata" y "enseguida nos sentimos en casa" (Lee, 1975). Pero se encontraban mejor que en sus casas: de su casa huyeron pero de aquí no se movían hasta que no recibían una oferta mucho mejor (Planells, 2002: 41) o la evolución de la sociedad ibicenca hacia mucho mejores otros lugares para vivir. Josefina Rodríguez cuenta la experiencia que vivieron Ignacio Aldecoa, ella misma y la hija de ambos, Susana, cuando llegaron a la isla por primera vez:

"Aunque ya conocíamos algunos puntos de la costa andaluza, levantina y catalana, Ibiza significó para nosotros el descubrimiento del Mediterráneo soñado. El Mediterráneo de las novelas y las películas. Un paraíso imaginado que nunca habíamos sospechado tan cercano. La isla era el resumen de todo lo que se nos negaba en el Madrid de aquella época. Un clima moral relajado. Un ambiente social cosmopolita de verdad. Extranjeros que vivían un exilio voluntario en las calas azules de la isla, ajena todavía a la agresión turística multitudinaria" (de Castro, 2003: 10).

Todos estos atractivos hicieron que se produjera una explosión de arte, de vida bohemia, a finales de los años cincuenta y durante los años sesenta. Ibiza cobijaba una o varias colonias de creadores internacionales, que frecuentaban Es Viver, Figueretes, Dalt Vila, La Marina, Sant Antoni y Santa Eulària. A título de anécdota se puede comentar que el agrónomo, militar retirado y ex-vicecónsul honorario de Holanda Hans van Praag, que residió durante años en Bali e Ibiza afirmaba que "Bali e Ibiza son completamente diferentes, pero tienen idéntico ambiente artístico, bonito, y con gente muy amable. Ahora allí, y aquí hay muchos turistas. Mi primera impresión cuando llegué a Ibiza es que el aire era como el de Bali. Allí también había muchos artistas: pintores, escultores, músicos" (Planells, 1980: 100).

El ambiente bohemio de Ibiza era frecuentado por extranjeros y personas de la península pertenecientes al mundo del arte que se caracterizaba por la convivencia e ignorancia 
mutua de personas de distintas ideologías, profesiones y orígenes, por situaciones aparentemente contradictorias y por un fuerte aislamiento del resto de la sociedad ibicenca, más tradicional y culturalmente atrasada. El poeta catalán Francesc Parcerisas afirmaba, refiriéndose a la falta de contacto entre la comunidad local y la comunidad foránea, y a que la cultura que se genera en la isla no se muestra en la isla "muchos son extranjeros, pocos son ibicencos, y se crea, en ocasiones una auténtica barrera idiomática entre las dos comunidades. Gente como Villangómez son desconocidas para casi todos los extranjeros, ¿qué extranjero puede haber leído a Villangómez en catalán? Pocos extranjeros lo conocen y lo leen. Y a veces viceversa. Son compartimentos estancos" (Planells, 1980: 26).

Jerry Hoke ejemplifica el típico extranjero radicado en la isla: "reconozco que no estoy metido dentro de la cultura de los ibicencos, no hablo vuestro idioma, aquí todos me hablan castellano o inglés y nos entendemos perfectamente. $\mathrm{Y}$ así llegamos a un punto que yo vivo mi vida y ellos viven la suya. Me tratan bien, me aprecian" (Planells, 1980: $39-40)$.

En aquella "Ibiza high Fifties" (Lee, 1975: 148-159), el bullicio de la Marina o el de Santa Eulària ya era motivo de reportajes en numerosos semanarios nacionales y europeos. París-Ibiza era un trayecto habitual entre los numerosos escritores franceses, holandeses, alemanes, norteamericanos, algunos de los cuales formaban parte del ya respetado grupo COBRA (Dotremont, Hugo Claus, Corneille, Appel). Charles Orloff describe la vida que llevaban en aquellos años los artistas que residían en las islas:

"Cuando llegué había en la isla algunos americanos y algunos alemanes, más escritores y poetas que pintores. Ahora es al revés. [...] Por la noche nos encontrábamos todos en la ciudad, para charlar, sin barreras de nacionalidad. Llegamos a reunirnos nueve nacionalidades, y todos teníamos como característica común la pobreza. Las consumiciones se las pagaba cada cual, y cada uno fumaba su tabaco. Vivía yo en Ibiza, con cincuenta dólares al mes. [...] Y nada de propinas. Cierto es que tampoco las esperaban" (Planells, 1980: 173).

Por si la complejidad del fenómeno no era suficiente, en los años cincuenta existían diversos ambientes sociales. Por una parte existía la capital, que concentraba la mayor parte de los artistas bohemios, siguiendo con la tradición iniciada en los años treinta, y era foco de atracción social de la población local de parte de la isla. Sant Antoni tenía menos artistas pero era más cosmopolita y turística, en definitiva era el destino para snobs y ciertos personajes que vivían de fiesta en fiesta. Sant Antoni era el foco de atracción de la población local que vivía en la parte de poniente de la isla y el entorno en el que aparecieron los palanqueros: "El mundo cosmopolita, snob, de San Antonio 
carecía de vías de comunicación directa con el mundillo bohemio, artístico, que se había formado, que se estaba desarrollando en la ciudad, y cuya culminación constituiría realmente un hito histórico en los anales ibicencos referidos al arte y la cultura" (de Castro, 2003: 75).

Finalmente en el resto de la isla, salvo algunos extranjeros que vivían apartados del mundillo de Sant Antoni o de la capital, perduraba una sociedad con un carácter más autóctono y con menos influencias producidas por los extranjeros.

Muchos de estos artistas compartían la visión romántica de una isla idílica donde las posibles deficiencias que padecía la población eran vistas como parte del exotismo del Mediterránea (Rodríguez, 2003: 42), tal y como comentaba Carlos Sansegundo al llegar a la Isla: " Una vez aquí pude sentir de cerca la gran libertad que ofrece Ibiza, libertad donde hasta el saber era libre" (Museu d'Art Contemporani, 1992: 39); o Hans Laabs: "cuando llegué a Ibiza, sentí en seguida que era el sitio que yo buscaba para olvidar un siglo de hierro, fuego y desgracias" (Planells, 1986: 30). Era paradójico comprobar como muchos artistas que habían vivido la dictadura nazi afirmaban tener libertad en un estado dictatorial como el franquista. La única explicación es la desconexión de estos artistas con la sociedad ibicenca y la relajación de la represión franquista en Ibiza (Rodríguez, 2003: 43). El franquismo apoyó o al menos toleró el arte contemporáneo en la mayoría de los casos y sólo lo reprimió cuando era obvia la vinculación entre arte y contestación política (Rodríguez, 2003: 79).

Generación Beat y beatniks. En los años cincuenta se produce un hecho que tendrá gran relevancia para el desarrollo turístico, la aparición de los beatniks. Se trata de un movimiento juvenil aparecido por aquella época en California (EE.UU.) que se caracteriza por seguir la cultura beat, la cual se basa en las ideas expresadas por los escritores de la Generación Beat. Probablemente, los beatniks descubrieron Ibiza a través de artículos de prensa aparecidos en Estados Unidos y cuyos autores los escribían desde Ibiza (Ramón, 2001: 75-76). La filosofía beat era básicamente contracultural, irracionalista, antiintelectualista, antimaterialista, anticapitalista y antiautoritaria, que remarcaba la importancia de mejorar la interioridad de cada uno más allá de las posesiones materiales. Los beatniks se autoexcluían del "sistema" llevándolos a huir de toda acción colectiva u organizada, por lo que su individualismo, llevado hasta las últimas consecuencias, limitaba su actividad a pequeños grupúsculos de marginados y artista (Granjon, 1985: 145-146; Phillips, 1995).

Aunque la importancia numérica y las actividades de los beatniks fueron poco visibles al mezclarse con los artistas e intelectuales, su presencia en la isla desde 1955 hasta bien entrados los sesenta resulto importante para dar a conocer la isla a los miembros del movimiento hippie. Los hippies, buscando los mismos enclaves que los beatniks, 
llegaron a Ibiza en gran número y dejaron una poderosa influencia en los años sesenta. La principal diferencia entre los beatniks y los hippies es el extremo individualismo de los primeros frente al espíritu comunitario y tribal de los últimos (Ramón, 2001).

En resumidas cuentas se puede afirmar que en los años cincuenta se produjo la llegada de la segunda oleada de intelectuales y artistas a la isla, tras la de los años treinta. Esta segunda remesa vino atraída por la difusión que realizaron los visitantes de los años treinta en determinados ambientes culturales.

\section{Actitudes de los residentes.}

La fase de implicación se caracteriza, precisamente, por el aumento muy significativo de la concienciación e implicación de una parte cada vez mayor de la población ibicenca en el nuevo sector económico. Las miserias económicas sufridas por la población en los años cuarenta, junto con los cambios que estaba viviendo el sector a nivel mundial, ayudaron a ello. En el primer tercio del siglo XX, la población llevaba una vida austera, pero con claras mejoras respecto a periodos anteriores, pero en la posguerra el bloqueo comercial vivido hizo que, por necesidad, los ibicencos buscaran una salida a la situación por cualquier vía, incluido el nuevo sector de la "economía de los visitantes".

Si la posguerra hizo que los residentes buscaran en el turismo una salida a su situación, los cambios en las sociedades emisoras de turistas (vacaciones pagadas, vuelos chárter, etc.) convirtieron una actividad reservada a unas élites en algo al alcance de mucha gente, y al aumentar el volumen de potenciales turistas aumento el atractivo del sector como actividad económica. Es decir, los ibicencos se empezaron a implicar en el turismo de forma significativa debido a una necesidad imperiosa, la pobreza generada por la posguerra, y a una mejora de perspectivas del sector a causa de los cambios en las sociedades emisoras.

La Administración fue abandonando las posturas más conservadoras posteriores a la Guerra Civil con el paso de los años. El régimen consideraba el turismo un mal necesario para obtener las divisas que financiasen las importaciones (Cirer, 2004: 188-189). El hecho de que la presión del régimen fuera menor hizo que la isla se convirtiera en "una discreta sala de espera para escritores, críticos de arte y artistas nacionales" (Planells, 2002: 39), es decir trabajaban y residían, al menos parte del año, en Ibiza a la espera de mejores tiempos, con más libertad, en las grandes ciudades de la península. La situación que encontraban en Ibiza es descrita por Josefina Rodríguez, esposa de Ignacio Aldecoa, en el prólogo de un libro de su marido: "En Ibiza nos sentimos inmersos en la libertad. Libertad en las conductas personales. Libertad en las costumbres. Libertad respetada y aceptada con naturalidad por los isleños. Parecía que habíamos encontrado 'la felicidad'. Peligrosa palabra que hay que escribir entre comillas" (Aldecoa, 1995). 
En esta fase del ciclo de vida del destino turístico se pueden diferenciar varios grupos de residentes: los extranjeros, los ibicencos que viven del campo y los ibicencos implicados en el sector turístico.

Los extranjeros, formados por artistas, intelectuales, beatniks y otros individuos que simplemente buscan una vida más tranquila y apacible. Este grupo de individuos forman una comunidad muy heterogénea, tienen comportamientos muy transgresores, incluso para sus sociedades de origen, y no se relacionan ni muestran interés por la población autóctona: "Si Ibiza ha sido Babel alguna vez -como pretenden muchos reportajes que emplearon esta imagen- fue entonces, es decir, a finales de los cincuenta y a principios de los sesenta. [...] Pues digno de lector atento en no confundir masa turística [...] con mesa artística, con taller creativo, con terraza alocada e imaginativa" (Planells, 2002: 40).

Identificados o no como beatniks, gran parte de estos extranjeros comparten sus señas de identidad, desde el rechazo a la forma de vida de la clase media hasta un elevado grado de individualismo, que les hará mantenerse al margen de cualquier acción colectiva organizada, lo cual les facilitará llevar una vida tranquila durante el franquismo (Cerdà y Rodríguez, 1999: 10). La falta de contacto con los ibicencos evita conflictos entre las dos comunidades y en los pocos puntos en los que se produce una cierta concurrencia de ambos grupos sociales se convierten en elemento de admiración para los jóvenes de la isla.

Los ibicencos más tradicionales seguían viviendo del campo. Una parte aún significativa de la población local seguía viviendo de la agricultura, tal y como hacían a principios de siglo. Esta parte de la población local se caracterizaba por estar compuesta principalmente por personas mayores que habían vivido toda la vida del campo y les costaba no sólo adoptar los cambios sino también entenderlos. A partir de los años cincuenta, la población dedicada a la agricultura se ira reduciendo al ritmo que estos individuos se vayan jubilando o muriendo, ya que ellos no cambian de sector económico y entre las nuevas generaciones no hay incorporaciones al sector, más allá de casos anecdóticos. A partir de los años setenta, la agricultura ya sólo será una actividad complementaria o un hobby para el fin de semana.

Los ibicencos implicados en el sector turístico. Este grupo estaba formado principalmente por los empresarios que empezaron a creer en el sector en décadas anteriores, nuevos empresarios que buscan en el turismo mejores beneficios y un gran número de jóvenes que quieren vivir mejor que sus padres y progresar. Hay que tener en cuenta que el sector industrial nunca fue apreciable en Ibiza y el sector primario vivió su último periodo de relativa bonanza en los años cincuenta, lo cual limitaba las alternativas laborales de la población. Si a ello sumamos que las personas dedicadas a la agricultura o la pesca 
tenían niveles de vida prácticamente de subsistencia y que en aquella época los trabajos en el sector servicios (esencialmente turismo) se encontraban en expansión y eran mucho mejor pagados, además de tener mayor "glamur" entre la población, es fácil comprender que muchos jóvenes buscaran su futuro profesional y vital vinculado al turismo.

A partir de los años cincuenta, muchos jóvenes al terminar los estudios obligatorios realizan cursillos de idiomas o de restauración a la vez que empiezan a trabajar como camareros, recepcionistas, guías turísticos, conductores de autobuses, taxistas, etc. Algunos de ellos trabajaban en temporada baja en las obras de construcción de hoteles, completando los ingresos que obtenían en verano. La implicación de estos ibicencos con el turismo no se resumía a trabajar en el sector, muchas veces en condiciones lamentables, sino que también vivían dentro del turismo: frecuentaban los establecimientos de ocio enfocados a los turistas, se bañaban en las playas frecuentadas por los turistas, etc. Planells lo comenta en los siguientes términos: "ibicencos ambiciosos pedían créditos para construir hoteles, mientras por las noches y a escondidas, aprendían inglés y amor libre, alemán y gestión de empresa, francés y libertad de pensamiento" (Planells, 2002: $31)$.

Un ejemplo del grado de inmersión de los jóvenes de la época en el ambiente turístico son los "palanqueros" que abundaban en Sant Antoni. Antoni Hormiga comenta el inicio de los "palanqueros": "Nuestras primeras relaciones con las turistas se solían limitar a hacer acto de presencia en Can Tarba. Aquello fue el nacimiento de los palanqueros, expresión que se hizo famosa años más tarde. [...] Por lo que recuerdo, los primeros turistas eran de una mediana edad, con jovencitas de unos cuarenta años y jovencitas de menos años..." (Planells, 1980: 185).

\section{CONCLUSIONES}

En los años cuarenta y cincuenta, los residentes se empezaron a implicar en el turismo de forma significativa debido a una necesidad imperiosa, la pobreza generada por la posguerra, y a una mejora de perspectivas del sector a causa de los cambios en las sociedades emisoras. Además se produjeron cambios de impacto brutal ya que se pasó de una sociedad tradicional a la vanguardia social mundial y de una sociedad poco compartimentada a una sociedad con compartimentos estancos que permiten que personas físicamente vecinas sean desconocidas. No sólo no había contacto entre los ibicencos y los extranjeros, sino que incluso los diversos grupos de extranjeros no mantenían casi ningún contacto. Planells lo comenta: "Parece increíble que los intelectuales de la época no se hubieran conocido, pero fue así: Ibiza siempre ha respetado esta forma estanca de comportamiento, estos microclimas humanos, las universales pequeñeces cotidianas..." (Planells, 2002: 33). 
La compartimentación e ignorancia mutua facilitó un ambiente de libertad y tolerancia. El escritor Peter Kinsley habla de la población local en los siguientes términos: "los ibicencos me gustan especialmente, más que los de la península, porque son tolerantes. Hacen su vida, y dejan a los demás hacer la suya. Eso es una buena cualidad. Son muy tranquilos con los extranjeros..." (Planells, 1980: 84). La situación vivida en los cincuenta se encuentra descrita de forma magistral por de Castro:

"Constituía Ibiza un lugar único, punto insólito de nuestra extensa geografía nacional. Insólito, digo, por la libertad de costumbres al uso, por el libertinaje [...] con que se comportaba una parte de la sociedad; el sector integrado por los extranjeros y por algunos peninsulares residentes [...]. Los ibicencos, en su inmensa mayoría, permanecieron inmunes a las modas extranjeras, enriscados en sus creencias y tradiciones ancestrales, pero sin escandalizarse tampoco por lo que veían sus ojos, ni, mucho menos, meterse a corregir yerros o pecados del prójimo. Esta, además, había sido una actitud suya histórica. Por otra parte, el clero, asombrosamente, permaneció neutro, atento sólo a su real feligresía, sin parar mientes en lo que hacía la gente extraña a la civita Dei. [...] Por otro lado, Ibiza quedaba muy a trasmano de Madrid, y tenía escasas comunicaciones con la satrapía de Palma de Mallorca, donde residía el gobernador civil y jefe provincial del Movimiento" (de Castro, 2003: 172-173).

Como vemos, las actitudes de esta fase del ciclo de vida de Ibiza se caracterizan por sus similitudes con las de los años treinta. Una parte importante, pero cada vez menor, de la población autóctona permanecía aun al margen del sector, viviendo del campo. Otra parte de la población autóctona, en rápido crecimiento, está compuesta por jóvenes con fuerte implicación en el sector. Los artistas e intelectuales extranjeros son muy pocos y permanecen apartados de la temática turística. Los Críticos son escasos y no muestran una oposición al turismo, más bien son neutrales. Sólo hay críticas significativas en los primeros años cuarenta y por parte de individuos vinculados al régimen, pero pronto desaparecen o se atenúan. El resto de grupos sociales aún no tienen presencia significativa. Por tanto, nos encontramos con un creciente número de personas sin opinión formada que pasan a ser partidarios del turismo a causa de las mejores condiciones de vida que ofrece el turismo respecto al campo.

Ibiza en los años cuarenta y cincuenta es un buen ejemplo de la influencia que posee la situación económica de la región en la implicación y el fomento de actitudes positivas por parte de los residentes, como ya indicaron otros autores (Allen et al, 1993; Lankford, 1994; Perdue et al, 1990). Las actitudes positivas generadas, combinadas con amplios niveles de tolerancia y respeto hacia las costumbres de los visitantes, son fundamentales para impulsar un potencial destino turístico. Estos elementos son los que hicieron posible que Ibiza se impulsara a la esfera internacional como destino turístico. 


\section{REFERENCIAS}

Aldecoa, I. (1995). Cuentos completos. Madrid: Editorial Alfaguara.

Allen, L. R., Hafer, H. R., Long, P. T. y Perdue, R. R. (1993). "Rural residents' attitudes toward recreation and tourism development". Journal of Travel Research, 32(1), p. 27-33. Allen, L. R., Long, P. T., Perdue, R. R. y Kieselbach, S. (1988). "The impact of tourism development on residents' perceptions of community life". Journal of Travel Research, 27(1), p. 16-21.

Buades, J. (2004). On Brilla el Sol. Turisme a Balears abans del Boom. Eivissa: Res Pública Edicions.

Butler, R. W. (1980). "The concept of a tourist area cycle of evolution: Implications for the management of resources". The Canadian Geographer, 24(1), p. 5-12.

Cerdà, J., y Rodríguez, R. (1999). La repressió franquista del moviment hippy a Formentera (1968-1970). Eivissa: Res Pública Edicions.

Cirer, J. C. (2001). Evolució de l'oferta de places turístiques a Eivissa i Formentera (1950-2000). Estudis sobre turisme a Eivissa i Formentera 2, 73-93. Eivissa: Editorial Mediterrània-Eivissa.

Cirer, J. C. (2002). L'economia d'Eivissa i Formentera en el segle XX. Palma de Mallorca: Edicions Documenta Balear S.L.

Cirer, J. C. (2004). De la fonda a l'hotel. La Gènesi d'una Economia Turística. Palma de Mallorca: Edicions Documenta Balear S.L.

de Castro, F. G. (2003). La isla perdida. Memoria de una época de Ibiza. Eivissa: Editorial Mediterrània-Eivissa.

Granjon, M. C. (1985). L'Amérique de la contestation. Les années soixanta aux Etats Unis. Paris: Presses de la Fundation Nationale des Sciences Politiques.

INE. Web Site: http://www.ine.es [31 de julio de 2012]

Johnson, J. D., Snepenger, D. J. y Akis, S. (1994). "Residents' perceptions of tourism development". Annals of Tourism Research 21(3), p. 629-642.

Jurowski, C. (1994). The Interplay of Elements Affecting Host Community Resident Attitudes toward Tourism: A Path Analytic Approach. Unpublished doctoral thesis, Virginia Polytechnic Institute and State University.

Lankford, S. V. (1994). "Attitudes and perceptions toward tourism and rural regional development". Journal of Travel Research, 24(3), p. 35-44.

Lee, L. (1975). I Cant't Stay Long. London: Penguin Books.

Martin, B. S. y Uysal, M. (1990). "An examination of the relationship between carrying capacity and the tourism lifecycle: management and policy implications". Journal of Environmental Management 31(4), p. 327-333.

Mason, P. y Cheyne, J. (2000). "Resident's attitudes to proposed tourism development". Annals of Tourism Research, 27(2), p. 391-411. 
Murphy, P. E. (1983). "Perceptions and attitudes of decisionmaking groups in tourism centers". Journal of Travel Research 21(3), p. 8-12.

Murphy, P. E. (1985). Tourism: A community approach. New York: Routledge.

Museu d'Art Contemporani (1992). Grupo Ibiza 59. Passat i Present. Eivissa: Museu d'Art Contemporani.

Perdue, R. R., Long, P. T. y Allen, L. (1990). "Resident support for tourism development”. Annals of Tourism Research, 17(4), p. 586-599.

Phillips, L. (edi.) (1995). Beat Culture and the New America: 1950-1965. New York: Whitney Museum of Art.

Pizam, A. (1978). "Tourism's impacts: the social costs to the destination community as perceived by its residents". Journal of Travel Research 16(4), p. 8-12.

Planells, A. (1984). Ibiza y Formentera, ayer y hoy. Barcelona: Antonio Planells Ferrer.

Planells, M. (1980). Ibiza, la senda de los elefantes, volumen I. Palma de Mallorca: Antigua Imprenta Soler.

Planells, M. (1986). Ibiza, la senda de los elefantes, volumen II. Barcelona: Ediciones Obelisco S. A.

Planells, M. (2002). El nacimiento de Babel -Ibiza años 60-. Eivissa: José Ferrer y Vicent Guillamó.

Ramón, E. (2001). Historia del turismo en Ibiza y Formentera. 1900-2000. Eivissa: Genial Ediciones Culturals.

Ritchie, J. R. B. (1988). "Consensus policy formulation in tourism: Measuring resident views via survey research". Tourism Management 9(3), 199-212.

Rodríguez, R. (2003). Avantguarda artística i societat a Eivissa (1933-1985). Eivissa: Res Pública Edicions.

Soriano, F. (1996). Pequeña historia del turismo en las Baleares. Palma de Mallorca: Bitzoc.

Torres, J. (1961). "Las comunicaciones marítimas con Ibiza”. Boletín de la Cámara Oficial de Comercio, Industria y Navegación de Palma de Mallorca n 630.

Williams, J. y Lawson, R. (2001). "Community issues and resident opinions of tourism". Annals of Tourism Research, 28(2), p. 269-290.

Zornoza, J. (1964). "El turismo en Ibiza, factor importantísimo de su economía". Boletín de la Cámara Oficial de Comercio, Industria y Navegación de Palma de Mallorca nº 644. 